The Israeli Journal of Aquaculture IJA.73.2021.1476638, 17 pages

CCBY-NC-ND-4.0 • https://doi.org/10.46989/001c.28258

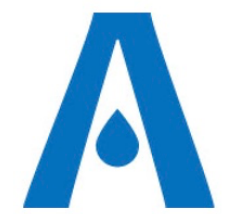

The $I J A$ is a peer-reviewed open-access, electronic journal, freely available without charge to users

Produced by the AquacultureHub non-profit Foundation Sale of $I J A$ papers is strictly forbidden

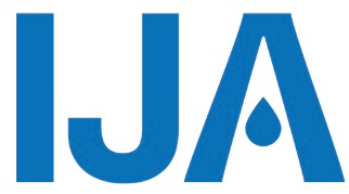

\title{
Evaluation of translocation impacts on genetic patterns in farmed and naturalized populations of Mytilus galloprovincialis along the China coast: clues from mitochondrial cytochrome c oxidase I sequences
}

\section{Mingkun Liu'1,3,5,6, Linying Yang1,2,3,5,6, Huayong Que ${ }^{1 *}$, Li Li13,4,5,6, Guofan Zhang 1,3,5,6}

${ }^{1}$ Key Laboratory of Experimental Marine Biology, Institute of Oceanology, Chinese Academy of Sciences, Qingdao 266071, China

2 University of Chinese Academy of Sciences, Beijing 100039, China

${ }^{3}$ Laboratory for Marine Biology and Biotechnology, Pilot National Laboratory for Marine Science and Technology, Qingdao 266237, China

${ }^{4}$ Laboratory for Marine Fisheries and Food Production Processes, Pilot National Laboratory for Marine Science and Technology, Qingdao 266237, China

${ }^{5}$ Center for Ocean Mega-Science, Chinese Academy of Sciences, Qingdao 266071, China

${ }^{6}$ National and Local Joint Engineering Laboratory of Ecological Mariculture, Qingdao 266071, China

Key words: Mytilus galloprovincialis, translocation, genetic diversity, differentiation, farmed vs. naturalized, COI

\begin{abstract}
As an introduced species, Mytilus galloprovincialis has developed into selfsustaining naturalized populations and has been widely cultivated in northern China. The M. galloprovincialis aquaculture industry wholly depends on the movement of naturalized juveniles onto farms. It is, therefore, necessary to understand the genetic effect of continuous spats' translocation. This study divided 12 localities of $M$. galloprovincialis along the China coast into three types of populations-farmed, naturalized adjacent farmed, and isolated-to investigate the genetic variation and differentiation. The genetic variability is reflected by haplotype diversity, nucleotide diversity, and the mean number of pairwise differences expressed as farmed populations $>$ naturalized adjacent farmed populations $>$ isolated populations. The Hierarchical analyses and Mantel-test indicated slight divergence between farmed and naturalized populations, northern and southern populations. The farmed and naturalized populations clustered into two separate categories in the neighbor-joining tree except two anthropogenically intervened localities. The present results suggest that the translocation practice positively affected genetic variability and played a vital role in shaping genetic composition. The information obtained in this study provides new insights into the impacts of the translocation culture model of marine mollusks.
\end{abstract}

* Corresponding author. e-mail: hque@jmu.edu.cn. Present address: Fisheries College, Jimei University, Xiamen 361021, China 


\section{Introduction}

Moving economically valuable aquaculture species to new regions is typical for conservation management and the commercial industry (Beaumont, 2000). The deliberate movement of populations can be usefully categorized into transfer (movement within a species' range) or introduction (movement outside a species' range) (Beaumont, 2000; Lemer and Planes, 2012). Depending on the particular situation, these changes may range from beneficial or harmful (Gaffney, 2006). When the transferred individuals are hatchery propagations, some genetic impact on the wild population is inevitable if the transferred stocks survive and reproduce (Castro et al., 2017). The primary issue focus on the changes in adequate population size and genetic composition of the wild populations (Gaffney, 2006; Lemer and Planes, 2012). The genetic effect between hatchery-produced and wild stocks has been widely studied in numerous aquaculture species, demonstrating a decrease of genetic variability in wild populations due to interbreeding with hatchery-propagations produced by limited parents (An et al., 2014; Behera et al., 2018; Rahman et al., 2009; Xing et al., 2014; Yu and Li, 2007). Different from the hatchery-propagations transfer, several studies concentrated on the effect of wild individuals transfers, named as translocation (Lemer and Planes, 2012). For commercial purposes between different regions, they recommend that the translocation homogenized the transferred and received populations, both in terms of genetic composition and variability (Arnaud-Haond et al., 2003, 2004). However, few empirical studies have been performed to study the effect of translocation among selfsustaining introduced populations named "naturalized" (Sutherland et al., 2020), like the Mytilus galloprovincialis scattered along the China coast. Like the wild populations, the translocation of naturalized populations is less likely to cause a reduction of adequate population size. However, it may increase genetic diversity and homogenization by pooling genetically divergent populations (Lemer and Planes, 2012).

Mussels are economically important bivalves in China aquaculture. The production of cultured mussels in China, primarily from three species-M. galloprovincialis, M. couscous, and Perna viridis-is more than 870 thousand tons (Bureau of Fisheries, 2020). Official statistics do not distinguish the output of individual mussel species. However, experts estimate that M. galloprovincialis, known as the Mediterranean mussel or blue mussel, account for about $55 \%$ of total production. These three mussels have relatively welldefined cultured regions. $M$. couscous and $P$. viridis are farmed in southern China, with $P$. Viridis, in Fujian and Guangdong provinces further south than those of $M$. coruscus, farmed mainly in Zhejiang province. The chief culture areas of M. galloprovincialis are along the coast of northern China, centering in the eastern waters of the Liaodong Peninsula and Haizhou Bay at the Shandong and Jiangsu province junction. Cultured under intertidal zone by the long-line or rope culturing techniques, the $M$. galloprovincialis grows faster, and meets sales specifications after the first growing season and spawns thousands of gametes in the next year (Wang, 1997).

The spread and cultivation of $M$. galloprovincialis in China occupy two distinct characters. Firstly, the wide distribution benefited from anthropogenic farming activities. M. galloprovincialis was introduced into China via ballast water from the Mediterranean Sea and initially identified in the 1950s in the northern Yellow Sea (Wang, 1997; Zhang et al., 1955). Due to its rapid growth and high production, combined with the success of natural seed collection, the culture of $M$. galloprovincialis became popular, forming a vast aquaculture industry after the 1970s. Meanwhile, M. galloprovincialis was deliberately moved southward to Zhejiang, Fujian, and Guangdong provinces widely from northern China for trial breeding in a short time (Zhang, 1984). As the problems of adaptation and transportation cost, the culture of $M$. galloprovincialis in southern China withered gradually and was replaced by indigenous species. To date, there is no large-scale transfer and culture in southern waters. However, the domestic or naturalized (self-sustaining introduced) populations (Sutherland et al., 2020) had left and isolated from northern populations (Pickett and David, 2018). Secondly, the aquaculture of M. galloprovincialis is exclusively based on the naturalized seeds rather than hatchery-produced individuals. Since the spawn time is not synchronized, the transplant of spats among chief culture regions is ubiquitous. For example, due to the higher temperature, the spawn time of $M$. 
galloprovincialis in Haizhou Bay is earlier than that in the Liaodong Peninsula. The farmers in the Liaodong Peninsula transplant spats from Haizhou Bay for earlier harvest and sale. Correspondingly, the farmers in Haizhou Bay supplement the seed from other laterspawning places for the seed shortage caused by disease, natural disaster, or the scaledculture demand. In addition, the farmers reflected that there is an advantage for non-local individuals in growth and survival for unknown reasons.

Several studies have investigated the genetic relationship of different $M$. galloprovincialis populations along the China coast, such as among natural populations (Han et al., 2017; Shen et al., 2011), cultured populations (Guo et al., 2012; Zhou et al., 2015), or between them (Pang et al., 2012). Evidence has confirmed the genetic homogeneity of the naturalized populations of M. galloprovincialis in China (Han et al., 2017; Shen et al., 2011). However, the conclusions of the other two aspects were unconvincing following the reasons as i: no species confirmation, especially for the southern populations due to the sympatry of $M$. coruscus with similar shell shape and possible hybridization (Chang et al., 2008; Shen et al., 2006; Yang et al., 2019), ii: minimal sampling sites that could not reflect the whole scenario between naturalized and farmed populations. Furthermore, no single study has considered the wild juvenile collection and artificial migrations. The genetic effect of translocation of $M$. galloprovincialis along the China coast requires further investigation to verify if the ongoing spats translocation of $M$. galloprovincialis increases gene flow among populations, leading to an increase in genetic diversity and decrease of genetic divergence among populations.

The capacity of the mitochondrial DNA (mtDNA) cytochrome c oxidase I (COI) gene to reveal ongoing genetic interactions between populations has been confirmed in extensive marine mollusks (Guo et al., 2015; Mao et al., 2011; Ni et al., 2012a, 2012b; Wang et al., 2017), including M. galloprovincialis (Gerard et al., 2008; Han et al., 2017; Pickett and David, 2018). The present study compared three populations from intensive sampling along the China coast: farmed, naturalized adjacent to the farm, and isolated naturalized populations by amplifying COI sequences. In addition, the levels of genetic diversity and population differentiation were evaluated, which provided a reference for the genetic evaluation of M. galloprovincialis or other commercially naturalized species relevant to the translocation culture model.

\section{sample collection}

\section{Materials and Methods}

A comprehensive survey of the M. galloprovincialis farming industry in China was conducted. We sampled i: individuals in M. galloprovincialis farms referred to as "farmed populations"; ii: naturalized individuals in regions absent from M. galloprovincialis farming in northern China, referred to as "naturalized adjacent farmed populations"; iii: naturalized individuals from southern China, referred to as "isolated naturalized populations" (Figure 1A, Table 1). Farmed mussels were mainly collected from chief culture regions: Dalian $(\mathrm{DL})$, Zhuanghe ( $\mathrm{ZH})$ in the east of the Liaodong Peninsula, and Ganyu (GY), Jiaonan (JN), surrounding the Haizhou Bay. Individuals from Aoshan (AS) were also collected and classified into the farmed population as small-scale farming in this locality. To avoid the interference of current-year-transplanting seedlings, we did not collect the farmed individuals directly. Still, we sampled from the reefs near farms or the breeding facilities, like floats, ropes, or cultivating boats. Naturalized adjacent to farmed individuals were collected from farming cages of oyster or scallop in Qinhuangdao (QHD), Changdao (CD), Kongtongdao (KTD), Rongcheng (RC), Rushan (RS). In these regions, the mussel is a kind of fouling organism for the other shellfish aquaculture. Isolated naturalized mussels were collected from offshore islands of Gouqidao (GQD) and Pingtan (PT) in southern China. The mantle was incised and frozen in liquid nitrogen and stored at $-80^{\circ} \mathrm{C}$ for DNA extraction. 

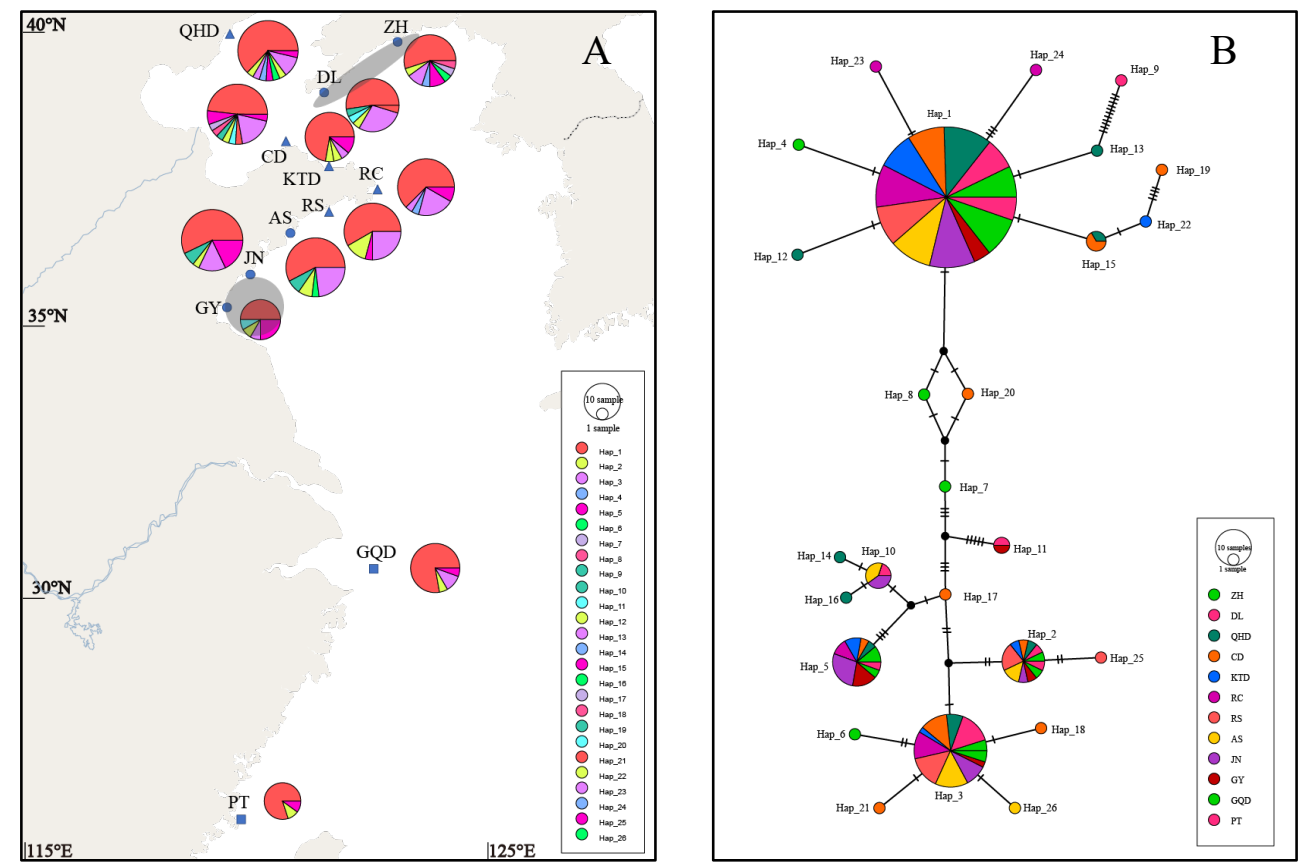

Figure 1 Spatial distribution (A) and network (B) of M. galloprovincialis haplotypes along the China coast. The size of circles is proportional to haplotype frequencies. A: variable symbols represent different types of populations: circle, farmed populations; triangle, naturalized adjacent farmed populations; square, isolated naturalized populations. Gray shading indicates the two main aquaculture waters: Haizhou Bay (round) and the eastern area of Liaodong Peninsula (oval). B: the haplotypes are separated by short segments as one mutation step in networks. Locality abbreviation is shown in Table 1.

Table 1 Sampling information and diversity indices of 12 localities along China coast

\begin{tabular}{|c|c|c|c|c|c|c|c|c|c|}
\hline Region & Population & Locality & $\begin{array}{c}\text { Locality } \\
\text { abbreviation }\end{array}$ & Coordinates & $N$ & $n$ & $h$ & $\Pi$ & $k$ \\
\hline \multirow{12}{*}{ Northern } & \multirow{6}{*}{$\begin{array}{c}\text { Farmed } \\
\text { populations }\end{array}$} & Zhuanghe & $\mathrm{ZH}$ & $39.49^{\circ} \mathrm{N}, 123.04^{\circ} \mathrm{E}$ & 20 & 8 & 0.7116 & 0.01159 & 7.1157 \\
\hline & & Dalian & DL & $38.86^{\circ} \mathrm{N}, 121.55^{\circ} \mathrm{E}$ & 21 & 6 & 0.6667 & 0.01356 & 8.3285 \\
\hline & & Aoshan & AS & $36.37^{\circ} \mathrm{N}, 120.73^{\circ} \mathrm{E}$ & 26 & 5 & 0.6246 & 0.01156 & 7.0953 \\
\hline & & Jiaonan & $\mathrm{JN}$ & $35.69^{\circ} \mathrm{N}, 119.93^{\circ} \mathrm{E}$ & 28 & 5 & 0.6376 & 0.01294 & 7.9471 \\
\hline & & Ganyu & GY & $34.97^{\circ} \mathrm{N}, 119.49^{\circ} \mathrm{E}$ & 12 & 5 & 0.7273 & 0.01542 & 9.4697 \\
\hline & & & Total & & 107 & 12 & 0.6556 & 0.01255 & 7.7055 \\
\hline & \multirow{6}{*}{$\begin{array}{l}\text { Naturalized } \\
\text { adjacent to } \\
\text { farmed } \\
\text { populations }\end{array}$} & Qinhuangdao & QHD & $39.63^{\circ} \mathrm{N}, 119.36^{\circ} \mathrm{E}$ & 27 & 9 & 0.6040 & 0.00963 & 5.9145 \\
\hline & & Changdao & $C D$ & $37.92^{\circ} \mathrm{N}, 120.69^{\circ} \mathrm{E}$ & 27 & 10 & 0.7464 & 0.01141 & 7.3162 \\
\hline & & Kongtongdao & KTD & $37.55^{\circ} \mathrm{N}, 121.52^{\circ} \mathrm{E}$ & 18 & 5 & 0.4837 & 0.00951 & 5.8366 \\
\hline & & Rongcheng & $\mathrm{RC}$ & $37.08^{\circ} \mathrm{N}, 122.50^{\circ} \mathrm{E}$ & 24 & 5 & 0.5797 & 0.01069 & 6.5616 \\
\hline & & Rushan & RS & $36.73^{\circ} \mathrm{N}, 121.49^{\circ} \mathrm{E}$ & 24 & 4 & 0.6051 & 0.01177 & 7.2246 \\
\hline & & & Total & & 120 & 18 & 0.6108 & 0.01072 & 6.5811 \\
\hline \multirow{3}{*}{ Southern } & \multirow{3}{*}{$\begin{array}{c}\text { Isolated } \\
\text { naturalized } \\
\text { populations }\end{array}$} & Gouqidao & GQD & $30.68^{\circ} \mathrm{N}, 122.69^{\circ} \mathrm{E}$ & 18 & 4 & 0.3987 & 0.00864 & 5.3072 \\
\hline & & Pingtan & PT & $26.68^{\circ} \mathrm{N}, 120.35^{\circ} \mathrm{E}$ & 10 & 3 & 0.3778 & 0.00898 & 5.5111 \\
\hline & & & Total & & 28 & 4 & 0.3810 & 0.00846 & 5.1958 \\
\hline
\end{tabular}

$N$ : number of individuals, $n$ : number of haplotypes, $h$ : haplotype diversity, $n$ : Nucleotide diversity, $k:$ mean number of pairwise difference

\section{Sequence acquisition and species confirmation}

Total genomic DNA was extracted from the mantle using the DNeasy tissue kit (Qiagen) accordingly. The sequence of the COI gene was amplified with the previously described primers (Folmer et al., 1994). The polymerase chain reaction (PCR) reaction mixture (10 ul) contained $0.8 \mathrm{ul} 2.5 \mathrm{mM}$ dNTPs, 1 ul $10 \times$ reaction buffer $\left(\mathrm{Mg}^{2+}\right.$ plus $), 1$ ul genomic DNA, $1 \mathrm{ul}$ of $10 \mathrm{uM}$ each primer and $0.05 \mathrm{ul} \mathrm{Taq} \mathrm{polymerase} \mathrm{(Takara).} \mathrm{The} \mathrm{PCR} \mathrm{procedure} \mathrm{was}$ performed under the following conditions: initial denaturation at $94^{\circ} \mathrm{C}$ for $3 \mathrm{~min}, 35 \mathrm{cycles}$ 
at $94^{\circ} \mathrm{C}$ for $1 \mathrm{~min}, 52^{\circ} \mathrm{C}$ for $1 \mathrm{~min}$, and $72^{\circ} \mathrm{C}$ for $1 \mathrm{~min}$, followed by a final extension at $72^{\circ} \mathrm{C}$ for $10 \mathrm{~min}$. The products of PCR were sequenced by Sangon Biotech (Shanghai) Co., Ltd.

Species confirmation was performed by comparing sequence similarity to the reference data set. Each distinct sequence was compared with available sequences in the GenBank database using the Basic Local Alignment Search Tool (BLAST) and rechecked on the BOLD (http://www.boldsystems.org/).

\section{Data analysis}

All sequences were assembled and modified by DNASTAR software (DNASTAR, Inc.). The package of Biopython 1.7 was used to treat sequences in Python 3.8, including sequence alignment, clipping, and format conversion. The number of haplotypes $(n)$, Haplotype diversity $(h)$, nucleotide diversity $(n)$, and the average number of nucleotide differences $(k)$ were calculated for each locality with DnaSP 6.1 (Rozas et al., 2017). Networks of haplotypes were estimated using Popart 1.7 (Clement et al., 2000). Finally, the mean distance and pairwise Fst among 12 localities were measured with MEGA X (Kumar et al., 2018) and Arlequin 3.5 (Excoffier and Lischer, 2010), respectively.

Hierarchical analyses of molecular variation (AMOVA) were performed in Arlequin 3.5 (Excoffier and Lischer, 2010) to estimate the population genetic structure following three grouped strategies as i: Three groups: farmed populations, naturalized adjacent farmed populations, isolated naturalized populations; ii: Two groups A: farmed populations, naturalized populations including naturalized adjacent farmed populations and isolated naturalized populations; iii: Two groups B: northern populations including farmed populations and naturalized populations adjacent farmed populations, southern populations equivalent to isolated naturalized populations. The variance components, the sum of squares, and $\Phi$ statistics were calculated between groups, among populations within groups, and within populations, respectively. The significance of $\Phi$-Statistics analogs $\left(\Phi_{\mathrm{CT}}, \Phi_{\mathrm{SC}}\right.$, and $\left.\Phi_{\mathrm{ST}}\right)$ was evaluated with $10^{5}$ random permutations. To verify the influence of spats exchange on the genetic distance between locations, Mantel-test was performed for all localities (northern localities and farmed localities) to examine the association between the Fst and geographical distance (log-transformed). An unrooted neighborjoining tree ( $\mathrm{NJ}$ tree) based on the genetic distance was constructed to evaluate the genetic relationships using the software PHYLIP 3.698 (Felsenstein, 2009) Figure 3.

Genetic variability

\section{Results}

Twenty-six haplotypes with 49 polymorphic sites (29 parsimony informative sites) were revealed according to the 614 bp COI segment in 12 localities. The sequences of haplotypes were deposited in the GenBank database with accession numbers MT581451 to MT581476. The genetic variation expressed by haplotype diversity, nucleotide diversity, and average number of nucleotide differences decreased from the farmed populations ( $h$ : $0.6556, \pi: 0.01255, k: 7.7055)$ to the naturalized adjacent farmed populations $(h: 0.6108$, $\Pi: 0.01072, k: 6.5811)$ and then the isolated populations ( $h: 0.3810, \pi: 0.00846, k$ : 5.1958) (Table 1). Two haplogroups were formed in the TCS network with no correspondent relationship with the geographical distribution of 12 localities (Figure 1B). Hap_1 was the sole haplotype shared in all 12 localities with an average frequency of $60 \%$, varying from $48 \%$ to $80 \%$ in each locality (Table 2 ). The CD belonging to the naturalized adjacent farmed population exhibited the highest haplotype diversity ( $h: 0.7467)$ and the largest haplotype number $(n=10)$ than all other localities. The isolated naturalized populations showed the lowest haplotype number (GQD: 4, PT: 3) and the highest frequency of Hap_1 (GQD: 78\%, PT: $80 \%$ ). 
Table 2 Haplotype distribution among localities

\begin{tabular}{|c|c|c|c|c|c|c|c|c|c|c|c|c|c|}
\hline & $\mathrm{ZH}$ & $\mathrm{DL}$ & QHD & $C D$ & KTD & $\mathrm{RC}$ & RS & AS & $\mathrm{JN}$ & GY & GQD & PT & $\mathrm{N}$ \\
\hline Hap_1 & 11 & 11 & 17 & 13 & 13 & 15 & 14 & 15 & 16 & 6 & 14 & 8 & 153 \\
\hline Hap_2 & 1 & 1 & 1 & 1 & 1 & & 3 & 2 & 1 & 1 & 1 & 1 & 14 \\
\hline Hap_3 & 2 & 6 & 3 & 5 & 1 & 5 & 6 & 6 & 4 & 1 & 2 & & 41 \\
\hline Hap_4 & 1 & & & & & & & & & & & & 1 \\
\hline Hap_5 & 2 & & 1 & 1 & 2 & 2 & & & 5 & 3 & 1 & 1 & 18 \\
\hline Hap_6 & 1 & & & & & & & & & & & & 1 \\
\hline Hap_7 & 1 & & & & & & & & & & & & 1 \\
\hline Hap_8 & 1 & & & & & & & & & & & & 1 \\
\hline Hap_9 & & 1 & & & & & & & & & & & 1 \\
\hline Hap_10 & & 1 & & & & & & 2 & 2 & & & & 5 \\
\hline Hap_11 & & 1 & & & & & & & & 1 & & & 2 \\
\hline Hap_12 & & & 1 & & & & & & & & & & 1 \\
\hline Hap_13 & & & 1 & & & & & & & & & & 1 \\
\hline Hap_14 & & & 1 & & & & & & & & & & 1 \\
\hline Hap_15 & & & 1 & 2 & & & & & & & & & 3 \\
\hline Hap_16 & & & 1 & & & & & & & & & & 1 \\
\hline Hap_17 & & & & 1 & & & & & & & & & 1 \\
\hline Hap_18 & & & & 1 & & & & & & & & & 1 \\
\hline Hap_19 & & & & 1 & & & & & & & & & 1 \\
\hline Hap_20 & & & & 1 & & & & & & & & & 1 \\
\hline Hap_21 & & & & 1 & & & & & & & & & 1 \\
\hline Hap_22 & & & & & 1 & & & & & & & & 1 \\
\hline Hap_23 & & & & & & 1 & & & & & & & 1 \\
\hline Hap_24 & & & & & & 1 & & & & & & & 1 \\
\hline Hap_25 & & & & & & & 1 & & & & & & 1 \\
\hline Hap_26 & & & & & & & & 1 & & & & & 1 \\
\hline
\end{tabular}

Hap = Haplotype; $\mathrm{N}=$ total number

\section{Genetic differentiation}

Genetic distance and pairwise Fst values ranged from 0.00844 to 0.01464 and $0.08037 \sim 0.06312$ with no static significance, respectively (Table 3). In addition, most of the pairwise comparisons of Fst values were negative. AMOVA was conducted for all the 12 sampling sites in three patterns (Table 4). All grouped strategies revealed significant variation among groups $(p<0.05)$ with low variance components $(1.57 \%, 1.74 \%$, and $3.15 \%$, respectively). 


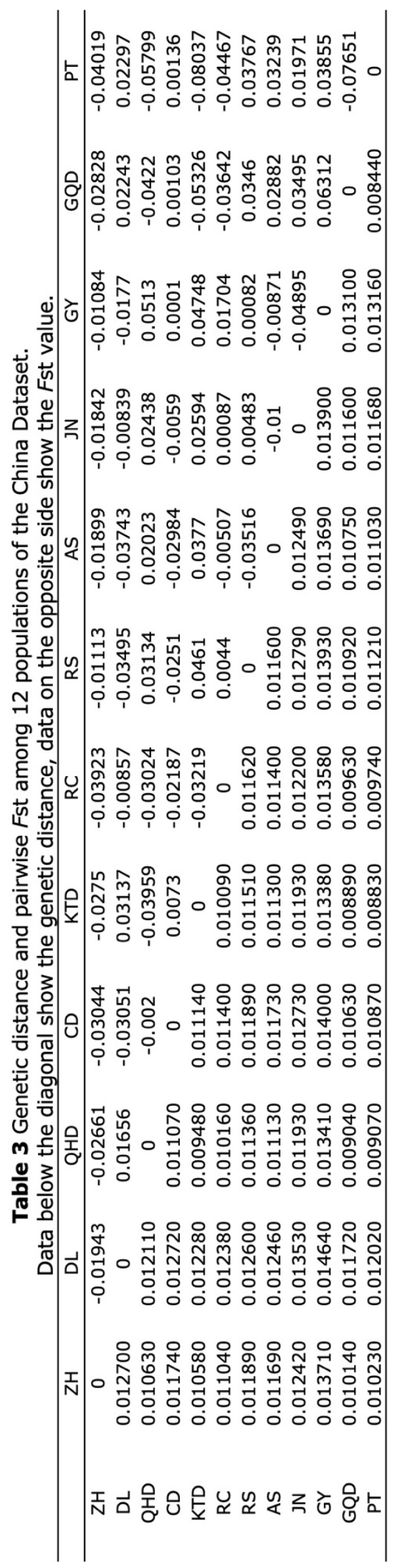

The Israeli Journal of Aquaculture - Bamidgeh • IJA.73.2021.1476638 
Table 4 Result of the analysis of molecular variance (AMOVA) testing the genetic structure

\begin{tabular}{|c|c|c|c|c|c|}
\hline Source of variation & D.F. & Sum of squares & $\begin{array}{c}\text { Percentage of } \\
\text { variation/\% }\end{array}$ & $\Phi$-Statistics & $P$-value \\
\hline \multicolumn{6}{|c|}{ Three groups ( $\mathrm{ZH}, \mathrm{DL}, \mathrm{AS}, \mathrm{JN}, \mathrm{GY})$, (QHD, CD, KTD, RC, RS), (GQD, PT) } \\
\hline Among groups & 2 & 13.109 & 1.57 & $\Phi_{\mathrm{CT}}=0.01569$ & $p<0.05$ \\
\hline Among populations within groups & 9 & 21.099 & -1.54 & $\Phi_{\mathrm{SC}}=-0.01562$ & 0.824 \\
\hline Within populations & 243 & 849.011 & 99.97 & $\Phi_{\mathrm{ST}}=0.00031$ & 0.584 \\
\hline \multicolumn{6}{|c|}{ Two groups A (ZH, DL, AS, JN, GY), (QHD, CD, KTD, RC, RS, GQD, PT) } \\
\hline Among groups & 1 & 9.928 & 1.74 & $\Phi_{\mathrm{CT}}=0.01745$ & $p<0.05$ \\
\hline Among populations within groups & 10 & 24.28 & -1.45 & $\Phi_{\mathrm{SC}}=-0.01478$ & 0.802 \\
\hline Within populations & 243 & 849.011 & 99.71 & $\Phi_{\mathrm{ST}}=0.00293$ & \\
\hline \multicolumn{6}{|c|}{ Two groups B (ZH, DL, AS, JN, GY, QHD, CD, KTD, RC, RS), (GQD, PT) } \\
\hline Among groups & 1 & 10.932 & 3.15 & $\Phi_{\mathrm{CT}}=0.03155$ & $p<0.05$ \\
\hline Among populations within groups & 10 & 20.626 & -2.63 & $\Phi_{\mathrm{SC}}=-0.02714$ & 0.936 \\
\hline Within populations & 252 & 1274.987 & 99.47 & $\Phi_{\mathrm{ST}}=0.00526$ & 0.848 \\
\hline
\end{tabular}

The Mantel-test revealed significant correlation between genetic and geographic distances for northern populations including farmed localities and naturalized adjacent farmed localities $(r=0.296, p<0.05)$. But no significant correlation was observed for all populations $(r=0.091, p>0.05)$ and farmed populations $(r=0.293, p>0.05)$ (Figure 2). 

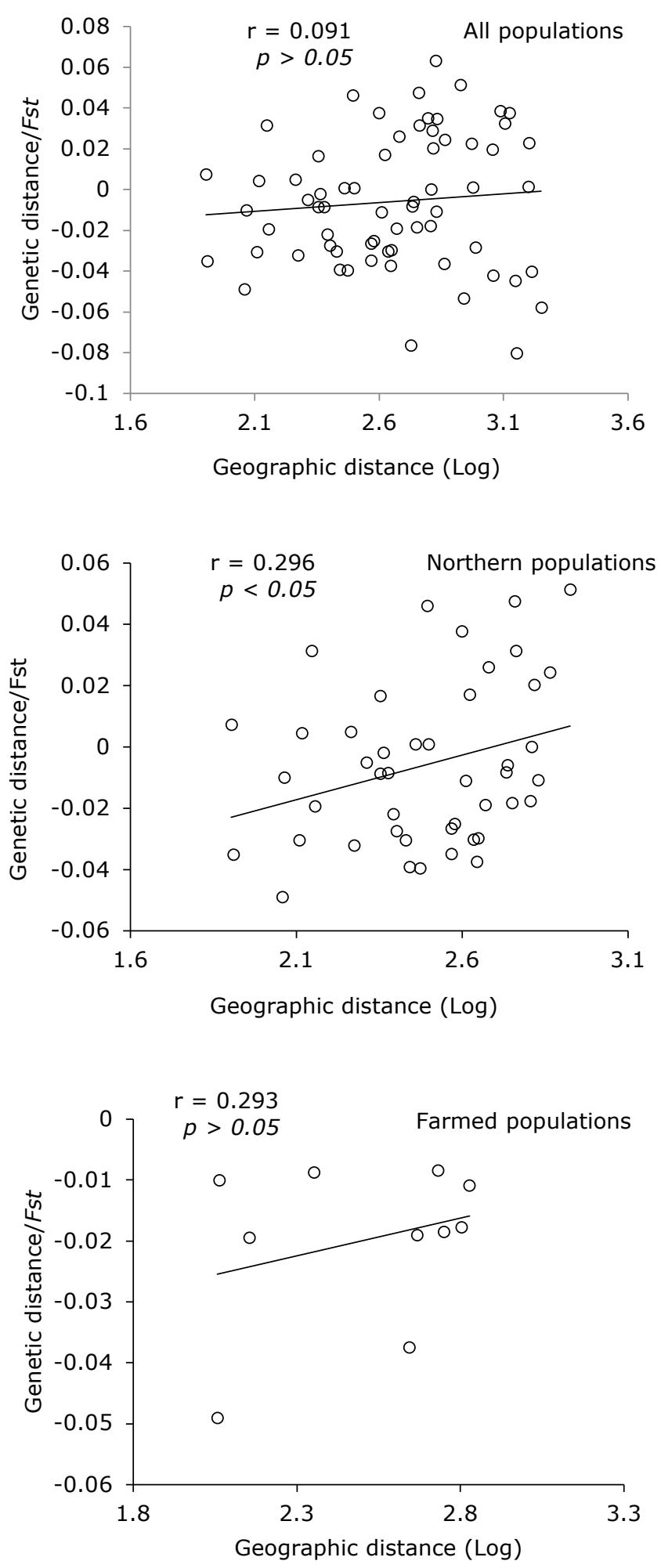

Figure 2 Isolation by distance plots for three grouped strategies of M. galloprovincialis. Relationship between genetic distance and geographic distance (log-transferred) for all populations, northern populations, and farmed populations. 
The NJ tree constructed based on genetic distances indicated that the 12 localities were allocated into three groups: one group including four naturalized localities (QHD, KTD, PT, and GQD), one group including four farmed localities (JN, GY, AS, and DL) and two naturalized localities (CD, RS), one group containing a separate locality of $\mathrm{ZH}$ (Figure 3 ).

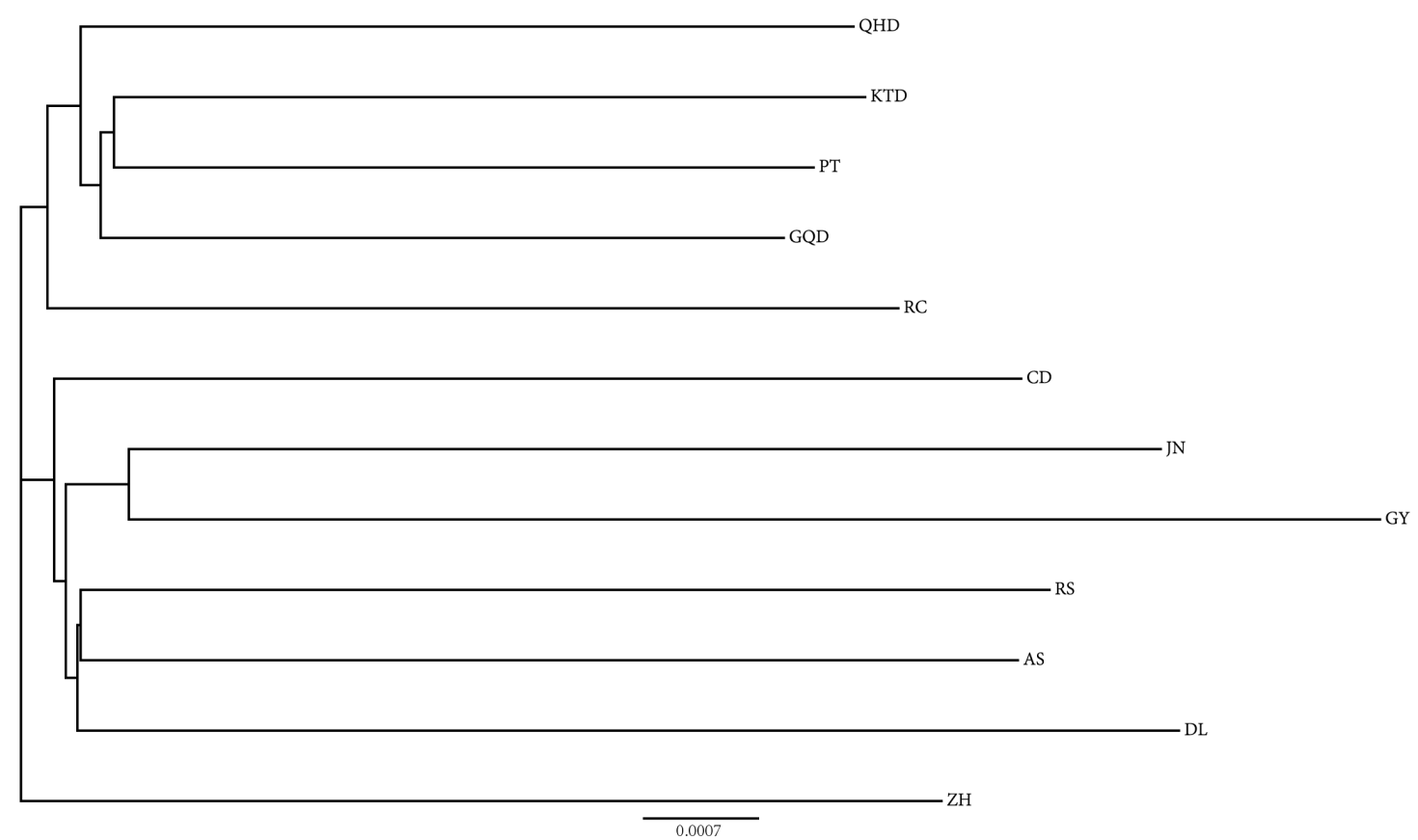

Figure 3 Neighbor-joining tree topology calculated by PHYLIP showing the genetic distance among 12 localities of M. galloprovincialis.

\section{Discussion}

Since before recorded history, humans have deliberately or accidentally carried biota with them when moving from one place to another (Beaumont, 2000). The failure of natural fisheries and the globalization of the aquaculture industry has resulted in increased pressure to move economically valuable aquaculture species to new regions (Beaumont, 2000; Rosenfield and Mann, 2019). Accidentally introduced into China from the Mediterranean Sea (Daguin and Borsa, 2000; Sanjuan et al., 1997), M. galloprovincialis has become an important aquaculture industry in the last 50 years (Zhang, 1984). As expected, the translocation culture model played an essential role in the genetic composition of this recently colonized species.

\section{Different levels of genetic variability and possible explanations}

The farmed populations exhibited the highest genetic variability in all three investigated populations measured by haplotype diversity, nucleotide diversity, and the mean number of pairwise differences. It is presumably due to the sizeable adequate population size and random mating within populations (Charlesworth, 2009). In the mussel cultivation industry, seed supply relies on the natural settlement of spats, or/and the spats transferred from other mussel farms, which keep the number of parents involved in reproduction at a high level (Philippe and Le, 2002; Rawson and Hilbish, 1998). Meanwhile, pooling juveniles from different cohorts with different genetic contexts promotes genetic heterogeneity in mussel farms (Lemer and Planes, 2012). Furthermore, commercial rope culturing may enhance gamete mixing and promote random mating within a population (Michalek et al., 2016). It is in line with the finding among Greek M. galloprovincialis populations where the genetic diversity of cultured populations was higher than that of wild populations, concluding that the translocation culture model played an important role in shaping patterns of genetic diversity (Giantsis et al., 2012). A similar result was also observed where human cultivation activities of transferring natural spats from the south to the north 
had greatly influenced genetic variation of Ruditapes philippinarum in China, exhibiting that the human-mediated populations exhibited high genetic diversity and genetic concordance (Hu et al., 2016; Liu et al., 2007).

The isolated naturalized localities, equivalent to southern populations, expressed the lowest genetic diversity. The interaction of several factors may account for this scenario. Firstly, the individuals transferred to the southern China were limited and only partial haplotypes were introduced. Mussel cultivation in southern China lasted briefly in the 1970s, followed by no commercial transfer and culture. Secondly, there was no gene exchange with northern populations. The Yangtze River with massive freshwater outflow acted as a putative physical barrier limiting pelagic larvae migration (Chen et al., 2009; Dong et al., 2012; Wang et al., 2003). Thirdly, un-adaptation to the environment. Random genetic drift and natural selection operated on all populations and tended to reduce genetic variability with decreased or loss of genetic traits, and the change of variants frequencies was faster in small populations (Avise, 1994). The provenance of China M. galloprovincialis was the northern basin of the Mediterranean Sea scattering from about $35^{\circ} \mathrm{N}$ to $45^{\circ} \mathrm{N}$ (Han et al., 2017; Hilbish et al., 2000), while the latitude of two southern localities was $30.68^{\circ} \mathrm{N}$ and $26.68^{\circ} \mathrm{N}$, respectively. The higher temperature conducted the thermal stress on the M. galloprovincialis in southern China. Therefore, the southern populations were in a state of continuous shrinkage, with offspring dramatically declining. Thus, limited individuals were left to propagate, leading to a rapid decreasing of genetic diversity caused by genetic drift (Charlesworth, 2009).

Sandwiched between two main culture areas, naturalized adjacent to farmed populations expressed middle-level genetic variability in all three compared populations. Heterogeneity could be transmitted from farmed populations to naturalized adjacent farmed populations due to interbreeding (Lemer and Planes, 2012). The prolonged planktonic larval stage and ocean currents offer the potential for geographic dispersal over distances, promoting the individuals' infiltration (Gilg and Hilbish, 2003; Liu et al., 2007; Michalek et al., 2016; Riginos et al., 2004). No mussel aquaculture in naturalized adjacent farmed localities but flooded with other shellfish farming like oyster or scallop. Mussels settled on the cages, or the shells of oysters/scallops could be transferred among localities by transporting these commercial species. Both factors increased the chance of individuals and genes exchange, but neither was comparable with artificial translocation within farmed populations.

The locality of Changdao (CD) showed exceptionally high haplotype diversity in all localities. Changdao is a hub site for the spat transfer between the Liaodong Peninsula and Haizhou Bay. The itinerary between Changdao and localities in the Liaodong Peninsula is by ship across the Bohai Strait. The itinerary between Changdao and Ganyu or Lianyungang in Haizhou Bay was by truck. Individuals may be left in the waters during the loading and unloading on the facility or the period of immerging into seawater when a connection is delayed. These individuals from populations over large geographical distances mate randomly, releasing genetic products and increasing the genetic variation in the new marine waters (Choudhuri, 2014; Giantsis et al., 2012,2014).

\section{Genetic structure}

The results of genetic distance, pairwise Fst, and Mantel-test for all populations illustrated no genetic differentiation of $M$. galloprovinciallis in China, consistent with previous studies (Han et al., 2017; Shen et al., 2011). No genetic differentiation was common in the recently introduced population (Palumbi, 1994). A homogenous genetic structure was also detected among the M. galloprovinciallis populations in South Africa (Zardi et al., 2018) and Eriocheir sinensis across the European populations (Hanfling et al., 2002), where introduced species arrived in in the late 1970s (Branch and Nina, 2004) and 1912 (Wang et al., 2008), respectively. The high dispersal and fecundity potential of marine invertebrates are expected to result in high gene flow among populations, leading to little to no signal of genetic differentiation (Gagnaire et al., 2015; Sutherland et al., 2020). The M. galloprovincialis was introduced into China over 150 years and rapidly 
expanded along the China coast by manual assistance. In China, there is insufficient time for M. galloprovincialis to attain migration-drift equilibrium combined with the translocation culture model, increasing the gene exchange among populations (Hossjer et al., 2016).

However, slight genetic divergence was detected with significance among groups when 12 localities were clustered into three or two groups based on the heterogeneity analysis. The strategy of "Two groups B" reflected the divergence between northern and southern populations. The isolation from northern populations and un-adaptation to the environment, combined with the habit competition coming from local species of $M$. coruscus and $P$. viridis (Li et al., 2013; Ye et al., 2012), led the southern populations to be a closed and small size group, where genetic drift is intensified (Hedgecock and Sly, 1990). The lowest haplotype diversity (GQD:0.399, PT: 0.378) and the lowest number of haplotypes (GQD:4, PT: 3) suggested a rapid genetic drift of southern populations. This finding supported the conclusion of a previous study conducted by Pickett and David (2018), who indicated that South China appeared to be a genetically isolated population.

Gene flow within a population can increase the population's genetic variation, whereas gene flow between populations can reduce the genetic difference and homogenized genetic structure (Choudhuri, 2014). Both strategies (Three groups and Two groups A) expressed genetic differentiation between farmed and naturalized populations. It could attribute to the translocation culture model, which increased gene exchange among farmed populations, consequently contributing to the genetic homogeneity and variation (Beaumont, 2000; Benke et al., 2009). It has also been confirmed that anthropogenic activities affected genetic composition in the areas like the Chilean (Toro et al., 2006), northwestern European coasts (Kijewski et al., 2011), and the central-eastern Mediterranean Sea (Giantsis et al., 2012, 2014), where spat transplantation for mussel aquaculture were common. The evidence from the Mantel-test supported the effect of the translocation culture model on the genetic divergence, where a significant correlation between genetic and geographic distance in northern populations was observed, whereas there was no correlation in farmed populations.

The NJ tree topologies yielded a clear separation between the farmed and naturalized populations with some vignettes. On the one hand, the $\mathrm{NJ}$ tree expressed that the $\mathrm{ZH}$, located in the northern Yellow Sea, separated with other clusters. It has been proven that the northern Yellow Sea was the first colonized waters of China M. galloprovincialis and the original tribe had more variation than other after-diffused populations under the founder event (Han et al., 2017). In contrast, the result that CD and RS were clustered into farmed groups reflected the anthropogenic impacts on genetic patterns of $M$. galloprovincialis in China. As mentioned above, the CD is the intersection of spat transfer among chief farmed localities, and there is little differentiation with farmed populations. In comparison, RS is the Pacific oyster farming and sales center in northern China, where thousands of juvenile or adult oysters were transported from other places for increasing fatness or sale. Thus, the mussel was transplanted along with the transportation of oysters as fouling organisms, reaching the genetic effect like CD or farmed populations.

This study assessed the genetic diversity and differentiation among M. galloprovincialis populations along the China coast. Comprehensively comparing the genetic diversity of three groups, the translocation practice seems to affect the genetic variability of the $M$. galloprovincialis positively. Slight but significant divergence was detected between farmed and naturalized populations, suggesting that spat transplantation was essential in shaping genetic composition. However, the genetic structure of a population is generally not static and is prone to change. The degrees of the changes depend on the intensity of interventions. Therefore, the genetic effect of translocation of China M. galloprovincialis requires long-term monitoring and in-depth evaluation. And clearly, more comparative investigations are still needed to test and extend the perspective, especially through integrating multiple genetic loci with extensive information like single nucleotide polymorphism. 


\section{Acknowledgements}

We thank Wu Fucun, Wang Qingzhi, Yu Zuoan, Huo Zhongming, Zhang Fuchong, Yu Tao, Wang Weijun, Zhang Yitao, Tan Lintao, Lin Zhishu, and Zheng Huaiping for samples collection. In addition, we thank Cong Rihao, $\mathrm{Xu}$ fei and $\mathrm{Li}$ Ao for their advice on the manuscript. The study was supported by the China Agriculture Research System of MOF and MARA (CARS-49).

\section{References}

An, H.S., Nam,M.M., Myeong, J.I., An, C.M. (2014). Genetic diversity and differentiation of the Korean starry flounder (Platichthys stellatus) between and within cultured stocks and wild populations inferred from microsatellite DNA analysis. Mol Biol Rep, 41(11), 72817292. doi:10.1007/s11033-014-3614-7

Arnaud-Haond, S., Vonau, V., Bonhomme, F., Boudry, P., Blanc, F., Prou, J., Seaman, T., Goyard, E. (2004). Spatio-temporal variation in the genetic composition of wild populations of pearl oyster (Pinctada margaritifera cumingii) in French Polynesia following 10 years of juvenile translocation. Mol Ecol, 13(7), 2001-2007. doi:10.1111/j.1365-294X.2004.02188.x

Arnaud-Haond, S., Vonau, V., Bonhomme, F., Boudry, P., Prou, J., Seaman, T., Veyret, M., Goyard, E. (2003). Spat collection of the pearl oyster (Pinctada margaritifera cumingii) in French Polynesia: an evaluation of the potential impact on genetic variability of wild and farmed populations after 20 years of commercial exploitation. Aquaculture, 219(1-4), 181-192. doi:10.1016/s0044-8486(02)00568-9

Avise, J. C. (1994). Molecular markers, natural history and evolution. New York: Chapman \&Hall. ISBN: 978-1-4615-2381-9

Beaumont, A. (2000). Genetic considerations in transfers and introductions of scallops. Aquaculture International, 8(6), 493-512. doi:Doi 10.1023/A:1009210404351

Behera, B.K., Kunal, S.P., Baisvar, V.S., Meena, D.K., Panda, D., Pakrashi, S., Paria, P., Das, P., Debnath, D., Parida, P.K., Das, B.K., Jena, J. (2018). Genetic variation in wild and hatchery population of Catla catla (Hamilton, 1822) analyzed through mtDNA cytochrome $b$ region. Mitochondrial DNA Part A, 29(1), 126-131. doi:10.1080/24701394.2016.1253072

Benke, M., Braendle, M., Albrecht, C., Milke, T. (2009). Pleistocene phylogeography and phylogenetic concordance in cold-adapted spring snails (Bythinella spp.). Molecular Ecology, 18(5), 890-903. doi:10.1111/j.1365-294X.2008.04073.X

Branch, G.M., Nina Steffani, C. (2004). Can we predict the effects of alien species? A case-history of the invasion of South Africa by Mytilus galloprovincialis (Lamarck). Journal of Experimental Marine Biology and Ecology, 300(1-2), 189-215. doi:10.1016/j.jembe.2003.12.007

Bureau of Fisheries, M. O. A., People's Republic of China. (2020). China fishery statistical yearbook. Beijing, China: China Agriculture Press. ISBN: 978-7-109-26847-0

Castro, M.C., Fileman, T.W., Hall-Spencer, J.M. (2017). Invasive species in the Northeastern and Southwestern Atlantic Ocean: A review. Mar Pollut Bull, 116(1-2), 4147. doi:10.1016/j.marpolbul.2016.12.048

Chang, K.M., Liu, H.H., Li, J.L., Shen, Y.B. (2008). A primary study on hybridization of Mytilus galloprovinciallis, Mytilus coruscus, heterosis of $F_{1}$ generation. Journal of Fisheries of China, (04), 552-557. doi:1000-0615(2008)04-552-06

Charlesworth, B. (2009). Fundamental concepts in genetics: effective population size and patterns of molecular evolution and variation. Nat Rev Genet, 10(3), 195-205. doi: $10.1038 /$ nrg2526

Chen, C.C., Shiah, F.K., Chiang, K.P., Gong, G.C., Kemp, W.M. (2009). Effects of the Changjiang (Yangtze) River discharge on planktonic community respiration in the East China Sea. Journal of Geophysical Research-Oceans, 114(C3), C03005. doi:Artn C03005 $10.1029 / 2008 j \mathrm{jc004891}$ 
Choudhuri, S. (2014). Fundamentals of Molecular Evolution. In S. Choudhuri (Ed.), Bioinformatics for Beginners (pp. 27-53). Oxford: Academic Press. doi.org/10.1016/B9780-12-410471-6.00002-5

Clement, M., Posada, D., Crandall, K.A. (2000). TCS: a computer program to estimate gene genealogies. Mol Ecol, 9(10), 1657-1659. doi:10.1046/j.1365-294x.2000.01020.x

Daguin, C., Borsa, P. (2000). Genetic relationships of Mytilus galloprovincialis Lamarck populations worldwide: evidence from nuclear-DNA markers. Evolutionary Biology of the Bivalvia, 177, 389-397. doi:Doi 10.1144/Gsl.Sp.2000.177.01.26

Dong, Y.W., Wang, H.S., Han, G.D., Ke, C.H., Zhan, X., Nakano, T., Williams, G. A. (2012). The impact of Yangtze River discharge, ocean currents and historical events on the biogeographic pattern of Cellana toreuma along the China coast. Plos One, 7(4), e36178. doi:10.1371/journal.pone.0036178

Excoffier, L., Lischer, H. E. (2010). Arlequin suite ver 3.5: a new series of programs to perform population genetics analyses under Linux and Windows. Mol Ecol Resour, 10(3), 564-567. doi:10.1111/j.1755-0998.2010.02847.x

Felsenstein, J. (2009). PHYLIP (Phylogeny Inference Package) version 3.698. Distributed by tha author. Department of Genome Sciences, University of Washington, Seattle.

Folmer, O., Black, M., Hoeh, W., Lutz, R., Vrijenhoek, R. (1994). DNA primers for amplification of mitochondrial cytochrome $c$ oxidase subunit I from diverse metazoan invertebrates. Mol Mar Biol Biotechnol, 3(5), 294-299. doi:PMID: 7881515

Gaffney, P.M. (2006). The role of genetics in shellfish restoration. Aquatic Living Resources, 19(3), 277-282. doi:10.1051/alr:2006028

Gagnaire, P.A., Broquet, T., Aurelle, D., Viard, F., Souissi, A., Bonhomme, F., Arnuad-Haond, S., Bierne, N. (2015). Using neutral, selected, and hitchhiker loci to assess connectivity of marine populations in the genomic era. Evolution Applications, 8(8), 769-786. doi: 10.1111/eva.12288

Gerard, K., Bierne, N., Borsa, P., Chenuil, A., Feral, J.P. (2008). Pleistocene separation of mitochondrial lineages of Mytilus spp. mussels from Northern and Southern Hemispheres and strong genetic differentiation among southern populations. Molecular Phylogenetics and Evolution, 49(1), 84-91. doi:10.1016/j.ympev.2008.07.006

Giantsis, I.A., Abatzopoulos, T.J., Angelidis, P., Apostolidis, A.P. (2014). Mitochondrial control region variability in Mytilus galloprovincialis populations from the central-Eastern Mediterranean Sea. Int J Mol Sci, 15(7), 11614-11625. doi: $10.3390 /$ ijms 150711614

Giantsis, I.A., Kravva, N., Apostolidis, A.P. (2012). Genetic characterization and evaluation of anthropogenic impacts on genetic patterns in cultured and wild populations of mussels (Mytilus galloprovincialis) from Greece. Genet Mol Res, 11(4), 3814-3823. doi: 10.4238/2012.August.17.14

Gilg, M.R., Hilbish, T.J. (2003). Patterns of larval dispersal and their effect on the maintenance of a blue mussel hybrid zone in southwestern England. Evolution, 57(5), 1061-1077. doi: 10.1111/j.0014-3820.2003.tb00316.x

Guo, B.Y., Qi, P.Z., Ye, Y.Y., Chu, Z.J., Wu, C.W. (2012). The genetic diversity and genetic structure of three cultured Mytilus edulis populations. Oceanologia et Limnologia Sinica, 43(1), 52-56. doi:10.11693/hyhz201201008008

Guo, X., Zhao, D., Jung, D., Li, Q., Kong, L.F., Ni, G., Nakano, T., Matsukuma, A., Kim, S., Park, C., Lee, H.J., Park, J. K. (2015). Phylogeography of the Rock Shell Thais clavigera (Mollusca): Evidence for Long-Distance Dispersal in the Northwestern Pacific. Plos One, 10(7), e0129715. doi:10.1371/journal.pone.0129715

Han, Z.Q., Mao, Y.L., Shui, B.N., Yanagimoto, T., Gao, T.X. (2017). Genetic structure and unique origin of the introduced blue mussel Mytilus galloprovincialis in the northwestern Pacific: clues from mitochondrial cytochrome $c$ oxidase I (COI) sequences. Marine and Freshwater Research, 68(2), 263-269. doi:10.1071/mf15186

Hanfling, B., Carvalho, G.R., Brandl, R. (2002). mt-DNA sequences and possible invasion pathways of the Chinese mitten crab. Marine Ecology Progress Series, 238, 307310. doi: $10.3354 /$ meps 238307 
Hedgecock, D., Sly, F. (1990). Genetic drift and effective population sizes of hatcharypropagated stocks of the Pacific oyster, Crassostrea gigas. Aquaculture, 88(1), 21-38. doi: 10.1016/0044-8486(90)90316-F

Hilbish, T.J., Mullinax, A., Dolven, S.I., Meyer, A., Koehn, R.K., Rawson, P.D. (2000). Origin of the antitropical distribution pattern in marine mussels (Mytilus spp.): routes and timing of transequatorial migration. Marine Biology, 136(1), 69-77. doi: $10.1007 / \mathrm{s} 002270050010$

Hossjer, O., Laikre, L., Ryman, N. (2016). Effective sizes and time to migration-drift equilibrium in geographically subdivided populations. Theor Popul Biol, 112, 139-156. doi:10.1016/j.tpb.2016.09.001

Hu, L.S., Zhang, Z., Ma, P.Z., Wang, H.Y. (2016). The genetic diversity of ten wild populations of Ruditapes philippinarum. Oceanologia et Limnologia Sinica, 47(3), 549-556. doi:10.11693/hyhz20150500142

Kijewski, T., Smietanka, B., Zbawicka, M., Gosling, E., Hummel, H., Wenne, R. (2011). Distribution of Mytilus taxa in European coastal areas as inferred from molecular markers. Journal of Sea Research, 65(2), 224-234. doi:10.1016/j.seares.2010.10.004

Kumar, S., Stecher, G., Li, M., Knyaz, C., Tamura, K. (2018). MEGA X: Molecular Evolutionary Genetics Analysis across Computing Platforms. Mol Biol Evol, 35(6), 15471549. doi: $10.1093 / \mathrm{molbev} / \mathrm{msy} 096$

Lemer, S., Planes, S. (2012). Translocation of wild populations: conservation implications for the genetic diversity of the black-lipped pearl oyster Pinctada margaritifera. Mol Ecol, 21(12), 2949-2962. doi:10.1111/j.1365-294X.2012.05588.X

Li, J.J., Ye, Y.Y., Wu, C.W., Qi, P.Z., Guo, B.Y., Chen, Y.J. (2013). Genetic variation of Mytilus coruscus Gould (Bivalvia: Mytilidae) populations in the East China Sea inferred from mtDNA COI gene Sequence. Biochemical Systematics and Ecology, 50, 30-38. doi: $10.1016 /$ j.bse.2013.03.033

Liu, J.X., Gao, T.X., Wu, S.F., Zhang, Y.P. (2007). Pleistocene isolation in the Northwestern Pacific marginal seas and limited dispersal in a marine fish, Chelon haematocheilus (Temminck \& Schlegel, 1845). Mol Ecol, 16(2), 275-288. doi:10.1111/j.1365-294X.2006.03140.x

Liu, X.Q., Bao, Z.M., Hu, J.J., Wang, S., Zhan, A.B., Liu, H., Fang, J.G., Wang, R.C. (2007). AFLP analysis revealed differences in genetic diversity of four natural populations of Manila clam (Ruditapes philippinarum) in China. Acta Oceanologica Sinica, 26(1), 150158. doi: CNKI:SUN:SEAE.0.2007-01-015

Mao, Y.L., Gao, T.X., Yanagimoto, T., Xiao, Y.S. (2011). Molecular phylogeography of Ruditapes philippinarum in the Northwestern Pacific Ocean based on COI gene. Journal of Experimental Marine Biology and Ecology, 407(2), 171-181. doi:10.1016/j.jembe.2011.06.002

Michalek, K., Ventura, A., Sanders, T. (2016). Mytilus hybridisation and impact on aquaculture: A minireview. Mar Genomics, 27(1876-7478 (Electronic)), 3-7. doi:10.1016/j.margen.2016.04.008

Ni, G., Li, Q., Kong, L.F., Zheng, X.D. (2012a). Phylogeography of bivalve Cyclina sinensis: testing the historical glaciations and Changjiang River outflow hypotheses in northwestern Pacific. Plos One, 7(11), e49487. doi:10.1371/journal.pone.0049487

Ni, G., Li, Q., Kong, L.F., Zheng, X.D. (2012b). Phylogeography of the bivalve Tegillarca granosa in coastal China: implications for management and conservation. Marine Ecology Progress Series, 452, 119-130. doi:10.3354/meps09624

Palumbi, S.R. (1994). Genetic divergence, reproductive isolation, and marine speciation. Annual review of ecology and systematics, 25(1), 547-572. doi:10.1146/annurev.es.25.110194.002555

Pang, Y.J., Li, J.J., Guo, B.Y. (2012). Genetic diversity evaluation on mitochondrial CO I gene between wild and cultured populations of Mytilus edulis. Journal of Anhui Agri. Sci., 40(14), 8068-8070. doi:10.13989/j.cnki.0517-6611.2012.14.142

Philippe, G., Le, M.O. (2002). Shellfish farming and Coastal Zone Management (CZM) development in the Marennes-Oléron Bay and Charentais Sounds (Charente Maritime, 
France): A review of recent developments. Aquaculture International, 10(6), 506-525. doi: 10.1126/science.187.4179.789-a

Pickett, T., David, A.A. (2018). Global connectivity patterns of the notoriously invasive mussel, Mytilus galloprovincialis Lmk using archived CO1 sequence data. BMC Res Notes, 11(1), 231. doi:10.1186/s13104-018-3328-3

Rahman, S.M., Khan, M.R., Islam, S., Alam, S. (2009). Genetic variation of wild and hatchery populations of the catla Indian major carp (Catla catla Hamilton 1822: Cypriniformes, Cyprinidae) revealed by RAPD markers. Genet Mol Biol, 32(1), 197-201. doi:10.1590/S1415-47572009005000013

Rawson, P.D., Hilbish, T.J. (1998). Asymmetric introgression of mitochondrial DNA among European populations of blue mussels (Mytilus spp.). Evolution, 52(1), 100-108. doi: $10.2307 / 2410924$

Riginos, C., Hickerson, M.J., Henzler, C.M., Cunningham, C.W. (2004). Differential patterns of male and female mtDNA exchange across the Atlantic Ocean in the blue mussel, Mytilus edulis. Evolution, 58(11), 2438-2451. doi:10.1111/j.0014-3820.2004.tb00873.x

Rosenfield, A., Mann, R. (2019). Dispersal of living organisms into aquatic ecosystems. USA: A Maryland Sea Grant Publication. doi:10.2307/1312468

Rozas, J., Ferrer-Mata, A., Sánchez-DelBarrio, J.C., Guirao-Rico, S., Librado, P., Ramos-Onsins, S.E., Sánchez-Gracia, A. (2017). DnaSP 6: DNA sequence polymorphism analysis of large data sets. Mol Biol Evol, 34(12), 3299-3302. doi: $10.1093 / \mathrm{molbev} / \mathrm{ms} \times 248$

Sanjuan, A., Zapata, C., Alvarez, G. (1997). Genetic differentiation in Mytilus galloprovincialis LMK. throughout the world. Ophelia, 47(1), 13-31. doi:10.1080/00785326.1997.10433387

Shen, Y.B., Li, J.L., Mu, Y.J. (2006). Molecular identification of introgression between the native Mytilus coruscus and the introduced Mytilus edulis using inter-simple sequence repeat marker(ISSR). Marine Fisheries, (03), 195-200. doi:10.3969/j.issn.10042490.2006.03.004

Shen, Y.B., Zhang, J.B., Feng, B.B., Li, J.L. (2011). Genetic diversity of blue mussel Mytilus galloprovincialis in China based on sequence analyses of mitochondrial COI gene. Marine Science Bulletin, 30(4), 435-440. doi:10.1016/s1671-2927(11)60313-1

Sutherland, B.J.G., Rycroft, C., Ferchaud, A.L., Saunders, R., Li, L., Liu, S., Chan, A.M., Otto, S.P., Suttle, C.A., Miller, K.M. (2020). Relative genomic impacts of translocation history, hatchery practices, and farm selection in Pacific oyster Crassostrea gigas throughout the Northern Hemisphere. Evol Appl, 13(6), 1380-1399. doi:10.1111/eva.12965

Toro, J.E., Castro, G.C., Ojeda, J.A., Vergara, A.M. (2006). Allozymic variation and differentiation in the chilean blue mussel, Mytilus chilensis, along its natural distribution. Genetics and Molecular Biology, 29(1), 174-179. Doi:10.1590/S141547572006000100031

Wang, B.D., Wang, X.X., Zhan, R. (2003). Nutrient conditions in the Yellow Sea and the East China Sea. Estuarine, Coastal and Shelf Science, 58(1), 127-136. doi:10.1016/s02727714(03)00067-2

Wang, C.H., Li, S.F., Fu, C.Z., Gong, X.L., Huang, L., Song, X., Zhao, Y. (2008). Molecular genetic structure and evolution in native and colonized populations of the Chinese mitten crab, Eriocheir sinensis. Biological Invasions, 11(2), 389-399. doi: 10.1007/s10530-008-9256-8

Wang, X.X., Kong, L.F., Chen, J., Matsukuma, A., Li, Q. (2017). Phylogeography of bivalve Meretrix petechialis in the Northwestern Pacific indicated by mitochondrial and nuclear DNA data. Plos One, 12(8), e0183221. doi:10.1371/journal.pone.0183221

Wang, Z. R. (1997). Fauna Sinica: Phylum mollusca. Order Mytiloida. Beijing, China: Science Press.ISBN: 9787030094858

Xing, K., Gao, M. L., Li, H. J. (2014). Genetic differentiation between natural and hatchery populations of Manila clam (Ruditapes philippinarum) based on microsatellite markers. Genet Mol Res, 13(1), 237-245. doi:10.4238/2014.January.17.7 
Yang, L.Y., Liu, M.K., Que, H.Y., Zhang, G.F. (2019). Comparison of growth and survival among the hybrid offspring of Mytilus galloprovinciallis and M. coruscus from laboratory crosses. Marine Sciences, 43(08), 552-557. doi:10.11759/hykx20190505001

Ye, Y.Y., Xu, M.Y., Guo, B.Y., Wu, C.W. (2012). Genetic structure and sequence analysis of four populations of Mytilus coruscus in the coastal water of southeast China sea using 16s RNA. Oceanologia et Limnologia Sinica, 43(02), 376-381. doi:CNKI:SUN:HYFZ.0.201202-033

Yu, H., Li, Q. (2007). Genetic variation of wild and hatchery populations of the Pacific oyster Crassostrea gigas assessed by microsatellite markers. J Genet Genomics, 34(12), 1114-1122. doi:10.1016/S1673-8527(07)60127-1

Zardi, G.I., McQuaid, C.D., Jacinto, R., Lourenço, C.R., Serrão, E.A., Nicastro, K.R. (2018). Re-assessing the origins of the invasive mussel Mytilus galloprovincialis in southern Africa. Marine and Freshwater Research, 69(4), 607-613. doi:10.1071/mf17132

Zhang, F.S. (1984). Mussel culture in China. Aquaculture, 39(1-4), 1-10. doi:10.1016/0044-8486(84)90255-2

Zhang, X., Qi, Z.Y., Li, J.M. (1955). The marine economic mollusk in northern China. Beijing, China: Science Press. ISBN:0001-1430

Zhou, C., Wu, C.W., Guo, B.Y., Chen, Y.J. (2015). Genetic diversity in ribosomal $18 \mathrm{~S}$ rRNA and mitochondrial COIII genes in Chinese cultured populations of mussel Mytilus galloprovincialis. Biochemical Systematics and Ecology, 59, 135-143. doi:10.1016/j.bse.2015.01.012 